\title{
Integrating the third way and third space approaches in a post-colonial world: marketing strategies for the business sustainability of community-based tourism enterprises in Vietnam
}

Tramy Ngo ${ }^{\mathrm{a}}{ }^{*}$, Gui Lohmann ${ }^{\mathrm{b}}$, Rob Hales $^{\mathrm{c}}$

\footnotetext{
a Griffith Institute for Tourism, Griffith University, Australia. Email: tramy.ngo@griffith.edu.au;

${ }^{\text {b} G r i f f i t h ~ A v i a t i o n, ~ G r i f f i t h ~ U n i v e r s i t y, ~ A u s t r a l i a . ~ E m a i l: ~ g . l o h m a n n @ g r i f f i t h . e d u . a u ; ~}$

${ }^{c}$ Griffith Business School, Griffith University, Australia. Email: r.hales@griffith.edu.au.
}

\begin{abstract}
This study investigates the potential to integrate third way and third space approaches for marketing community-based tourism enterprises (CBTEs) in less-developed countries. The outcome of this integration is reflected in marketing strategies oriented towards the business sustainability of CBTEs in Vietnam. In particular, proposals on three aspects of CBTE marketing, including market segmentation, product design and development, and product communication and promotion, are illustrated. Through the proposed marketing strategies, the research contributes to CBT theory by showing that paradoxical CBT problem domains can be better addressed by integrating different ideological and developmental approaches. Additionally, the strategies provide evidence-based, practice-driven guidance for the extensively evaluated but insufficiently tackled marketing issues for CBTEs in Vietnam.
\end{abstract}

Keywords: CBTEs, collaborative marketing, third way, third space, Vietnam

\section{Introduction}

Community-based tourism enterprises (CBTEs) have been widely recognised as an enterprisebased development model capable of maximising the benefits and minimising the negative impacts of tourism on a community. A CBTE is defined as a micro-scaled business located in a

\footnotetext{
*Corresponding author: tramy.ngo@griffith.edu.au
} 
rural or remote area of a less-developed country and is characterised by the following fundamental attributes: it is owned, managed and operated by a local community, and it benefits that community (Manyara \& Jones, 2007). A CBTE can be in the form of a communityrun business or a venture of a community household with contributions to the community. CBTEs have proliferated in less-developed countries as a mechanism for community transformation (i.e., empowerment, poverty alleviation, increased income, livelihood diversification, cultural conservation and environmental protection), which in turn contributes to sustainable tourism at a destination (Tasci, Croes, \& Bartels Villanueva, 2014; Zapata, Hall, Lindo, \& Vanderschaeghe, 2011). However, these potential benefits of CBTEs can be activated only if a CBTE is commercially viable.

Among other management dimensions, marketing plays a crucial role in the business sustainability of CBTEs (Mitchell \& Muckosy, 2008; Okazaki, 2008). A recurrent reason for the failure of CBTEs in less-developed countries is poor market access (Dixey, 2008; Häusler, 2008; Mielke, 2012). This operational challenge mainly occurs due to the physical remoteness of CBTEs as well as a lack of tourism know-how and marketing incompetence among local entrepreneurs (Espeso-Molinero, Carlisle, \& Pastor-Alfonso, 2016; Notzke, 2004).

Discussions of marketing and CBTE business sustainability clearly show that CBTE marketing activities should consider the dual objectives of CBTE financial viability and sustainability priorities to be successful. CBTE business sustainability and CBTE long-term success are terms used in this research to describe the combination of financial viability and community development priorities. The dual objectives of CBTE sustainability have been widely identified as creating a self-sustaining business that preserves indigenous values and enhances community well-being (Carr, Ruhanen, \& Whitford, 2016; Manyara \& Jones, 2005). Indeed, Ngo, Lohmann, and Hales (2018) argue that to achieve long-term success, CBTEs should pursue the attainment of the dual objectives in their marketing strategies through balancing the contradictive tourism development approaches included in CBTE marketing. Despite the recent attention directed towards these challenges, there is still a lack of research examining the efforts to balance the tourism paradoxes in the context of CBTE marketing and promote the fulfillment of the dual objectives for business sustainability in CBTE marketing strategies. 
The concept of collaborative marketing is involved in the efforts to delineate marketing initiatives oriented towards CBTE sustainability. Regardless of different developmental approaches, CBTEs always require marketing assistance from external stakeholders, such as tour operators or philanthropists (Reggers Grabowski, Wearing, Chatterton, \& Schweinsberg, 2016; Sakata \& Prideaux, 2013; Zapata et al., 2011). However, post-colonialisation is also associated with the involvement of external stakeholders in CBTE marketing strategies. Thus, optimising the potential benefits of stakeholder collaboration in CBTE marketing while simultaneously minimising the hazards of post-colonialisation embedded in marketing partnerships is crucial to developing CBTE marketing strategies.

The present study aims to address the challenges outlined above by integrating the third way approach in CBT development and the third space approach in CBT marketing for the purpose of exploring a marketing strategy that prioritises the long-term success of CBTEs. The paper's objectives are twofold: (1) to investigate the significance of integrating ideological approaches to better orient marketing endeavours towards the business sustainability of CBTEs and; (2) to configurate the components of a marketing strategy for CBTE long-term success in Vietnam.

The paper is structured in six sections. After the Introduction, the Literature review section presents the justification for integrating the third way approach in CBT development and the third space approach in CBT marketing to theoretically frame a CBTE marketing strategy for business sustainability. Then, in the Methodology section, the constructivist paradigm and the knowledge co-production approach are employed to guide the research design. Next, the Findings section illustrates the marketing strategies in market segmentation, product design and development, and product communication and promotion for CBTEs in Vietnam. The discussion section follows, in which the contribution of the study are described. Finally, the conclusion section summarises the research findings, research limitations and indicates potential avenues for future research based on the contribution of the present study.

\section{Literature review}

Polarised CBTE marketing strategies and their responsiveness to the business sustainability of CBTEs in less-developed countries 
The literature on CBTEs in less-developed countries highlights a range of dichotomies with regard to CBTE marketing strategies. The scope of the less-developed countries set in this study is aligned with the category of emerging and developing economies used by the International Monetary Fund (IMF, 2015, April). Based on this category, and with reference to the development of CBT in different parts of the world, the marketing activities of CBTEs in African, Latin American, and Asian countries are examined. In particular, in a post-colonial era, polarities in targeted markets and market segmentation of CBTEs, dilemmas in the marketisation of CBT products, and the paradoxical linkages between local entrepreneurs and travel intermediaries are investigated.

International travellers have shown substantial interest in the offerings of CBTEs in lessdeveloped countries. In addition to the mainstream flows of international tourists crossing national borders for leisure, exoticism and novelty seeking (Kontogeorgopoulos, Churyen, \& Duangsaeng, 2013; Phommavong \& Sörensson, 2012), the international market of CBTEs in less-developed countries is also configured by niche segments. CBTEs can stimulate tourist flows from developed regions to less-developed countries for goodwill and fair-trading tourism purposes (Evan \& Cleverdon, 2000; Schéou \& Southon, 2013). The networks of donors, NGOs, and international development agencies in the developed world also represent a source of international visitors to donors-funded, NGOs-aided CBTEs in the developing world, as indicated in the study of Zapata et al. (2011). However, due to the insufficient knowledge and skills, many local entrepreneurs are passively dependent on international tour operators, external sponsors, and other intermediaries to access the market (Schéou \& Southon, 2013; Van Der Duim \& Caalders, 2008). This passive dependence results in benefit leakages, foreign resource control, changed positions of local entrepreneurs in value chains, and even business collapse after a funded period (Dixey, 2008; Manyara \& Jones, 2007; Zapata et al., 2011).

Polarised market segmentation approaches, i.e., niche market versus mainstream market, differentiate CBTE marketing strategies. Some CBTEs are marketed to a niche market, the travellers to which are most likely wealthy, highly educated, and intrinsically interested in indigenous values and community benefits (Notzke, 2004). However, the limited size of niche markets challenges the practicality of this approach (Notzke, 2004). In contrast, there are 
efforts to integrate CBTEs' products into mainstream tourism through linkages between CBTEs and tour operators. However, these efforts confront the issue of product quality. Van Der Duim and Caalders (2008) illustrate a service quality gap, in which local partners fail to meet the requirements of industry partners. Additionally, issues involving commoditised authenticity, dissension within the community and between community members and private partners are associated with this approach (Häusler, 2008; Koot, 2016).

The marketisation of CBT products offered by CBTEs in less-developed countries is confronted with the antitheses of authenticity versus inauthenticity, and modern versus primitive. In his ethnographic study of the !Xaus Lodge (South Africa), Koot (2016) depicted this contradiction. The !Xaus Lodge is promoted as a CBTE owned by the ¥Khomani San (Bushmen) and Mier communities in South Africa (https://www.xauslodge.co.za/about-us). According to Koot (2016), the Bushmen are conventionally encouraged to museumise themselves to represent the $¥$ Khomani - hunter-gather groups in the region at the beginning of the twentieth century. This role play was due to a conventional trend in CBT experience that tourists would not "book an expensive lodge deep in the Kalahari to see Bushmen working behind computers" (Koot, 2016, p.1216). Through role performances and traditional dress, the Bushmen stay authentic to attract tourists, who in turn impose modernity as consumers. To this end, the Bushmen (and their authenticity) are regarded as a tourism product. This commodification and brand-building of indigenous people are inherently incompatible with the inevitable inauthenticity associated with capitalism, economic development, and modernity brought about through tourism. Concomitantly, this CBT commodification also clashes with the objective of "community empowerment" that external stakeholders, including tourism operators, propagandise in their interventions with this CBTE. Indeed, the common knowledge that "tourists do not come all the way to this small village only to be shown blenders, $\mathrm{t}$-shirts emblazoned with sports team logos and other signposts of all things modern" reflects the contradiction between modern and primitive in "selling" CBT products (Taylor, 2014, p. 219).

Related to the contradiction in the commercialisation of CBT products and the polarisation between niche market versus mainstream market segmentation strategies is the paradoxical linkage between local entrepreneurs and travel intermediaries. The selection of market 
segments and the positioning of CBT products as a tourism commodity affect the extent to which the power relationships between local entrepreneurs and tourism operators are balanced. Tolkach and King (2015) argued that, by targeting visitors who accept limited services from local hosts, prioritising learning from hosts and appreciating solidarity in interactions with local entrepreneurs, CBTEs can leverage their bargaining power with tourism operators. Koot (2016) implied that by portraying local communities as representing authenticity to appeal tourists, imperialism is further reinforced in the relations of visitors and tourism intermediaries with local communities.

\section{Underlying challenges for CBTE marketing strategies}

Debates on CBT principles emerge from the abovementioned CBTE marketing strategies. At the ideological level, the paradoxical marketing strategies of CBTEs in less-developed countries are related to the opposition between post-colonialism and de-colonialism. Postcolonialism and de-colonialism are alternative approaches to addressing the power relations in multi-actor relationships. Post-colonialism refers to relations between the colonised and coloniser, which re-emerge in situations in which independent countries suffer from the intervention and control of external states (Hall \& Tucker, 2004). CBTE marketing is regarded as an easily colonised domain of CBT development for two reasons: the inherent business incapability of local entrepreneurs and the expertise and business skills required for this task (Malatji \& Mtapuri, 2012; Mitchell \& Muckosy, 2008; Okazaki, 2008). Additionally, the product offerings of CBTEs cannot be isolated from the influence of tourists, supply chains, foreign tour operators and other travel intermediaries (Manyara \& Jones, 2007; Tolkach \& King, 2015; Van Der Duim \& Caalders, 2008). Accordingly, numerous studies have attempted to balance the power relationships between local communities and external stakeholders in CBT development through a decolonialism-oriented approach. Among these efforts are the bottom-up, locally initiated, non-monetised CBT model proposed by Sakata and Prideaux (2013), the bottom-up, locally initiated, domestic market-targeted CBT model of Zapata et al. (2011), and the bottom-up CBT model of Reggers et al. (2016).

With regards to development viewpoints, paradoxes in the potential target markets, market segmentation strategies, CBT marketisation, and in the linkages between local entrepreneurs and tourism intermediaries exemplify the antithesis between neoliberalism and 
protectionism. A neoliberal approach emphasises the significance of individualised economies, market liberalisation, and laissez-faire economic strategies characterised by minimal interventions of the government in trading processes (Öniş \& Şenses, 2005; Scheyvens, 2007). In contrast, protectionism focuses on tourism as a social force (HigginsDesbiolles, 2006). Under the neoliberal approach, marketing is considered an economic tool that is crucial for leveraging the market appeal of CBTEs. An outstanding example of this viewpoint is reflected in the attempts to outsource CBTE marketing to private partners under joint venture partnerships and in the mainstream segmentation approaches of CBTEs (Torres, Skillicorn, \& Nelson, 2011; Van Der Duim \& Caalders, 2008). However, supporters of protectionism argue that a commercialisation-driven direction associated with marketing tools can impact the ability of a CBTE to achieve its development objectives. Thus, flows of philanthropic travellers and niche marketing segmentations are encouraged. Similarly, under the neoliberal ideology, CBTE marketing strategies are characterised by market-driven approaches, private corporation hegemony and commercial viability goals. Meanwhile, within the protectionist approach, CBTE marketing strategies focus on community well-being and social goals (Ngo et al., 2018). To this end, it becomes evident that the dichotomy of CBTE marketing strategies is fundamentally rooted in the difference in ideological viewpoints and development approaches embedded in the domain of CBT development.

The CBT literature also indicates that neither of the above-mentioned schools of thought and development viewpoints can solely lead to CBTE business sustainability. Regardless of the priority given to community empowerment and non-economic objectives, the bottom-up, decolonial-oriented CBT models admit the necessity of (marketing) assistance from external stakeholders. For instance, Reggers et al. (2016) suggest a model that is driven by the community, but works in partnership with tour operators and philanthropists. Similarly, Sakata and Prideaux (2013) recognise the necessity of tourism marketing assistance from external organisations for sustainable practices in their proposed CBT model. Thus, postcolonialism cannot be completely eliminated in the realm of CBTE marketing. The entanglement between CBTE marketing and post-colonialism is relevant as long as CBTEs are still a tourism business in the tourism system (Tolkach \& King, 2015). Similarly, it is argued that the interference-free neoliberal approach is ineffective in framing CBTEs over the longterm (Koot, 2016; Snyman, 2014). For instance, the remedy of outsourcing CBTE marketing to 
tour operators, which often occurs in joint venture partnerships between a CBTE and a private partner, may leverage the commercial viability of a venture without proper consideration of the conservation and well-being objective (Manyara \& Jones, 2005). Meanwhile, the solely protection-driven approach is inappropriate for CBTEs that embraces economic activities. The practices of CBTEs in less-developed countries indicate that CBTE projects prioritise the attainment of development objectives without proper consideration of the business' commercial viability would often result in the collapse of the business (Dodds, Ali, \& Galaski, 2016; Häusler, 2008; Mielke, 2012).

Instead, the potential of alternative approaches in CBT product development and CBT marketing co-efforts have recently been advocated to tackling CBT challenges at the grassroots level (Espeso-Molinero et al., 2016; Ngo et al., 2018; Ngo, Hales \& Lohmann, 2019). Under neo-liberalism, CBTEs should be aware of both the market-driven nature of marketing practices and the transformative capacity of marketing tools for the community. However, studies have not articulated whether these alternative approaches to CBTE marketing practices will lead to long-term success. This study aims to fill this gap by advocating a favourable ideological context for marketing strategies oriented towards the long-term success of CBTEs.

The third way and third space approaches in CBT and their incorporation as drivers of marketing practices towards CBTE long-term success

The potential of the third way approach is increasingly advocated in tourism development studies. According to Giddens (1998, p.26), the third-way approach is "a framework of thinking and policymaking that seeks to adapt social democracy to a world which has changed fundamentally over the past two or three decades. It is a third way in the sense that it is an attempt to transcend both old-style social democracy and neoliberalism" (cited in Burns, 2004). In tourism, the third way approach is characterised by certain attributes. The approach proposes alternative sets of arguments about tourism planning and development through an understanding of the contradictions and tensions between the Development First approach and the Tourism First approach to sustainable development (Burns, 2004). In addition, the third way approach acknowledges the need to balance idealism and pragmatism in tourism endeavours based on the nuanced linkages between tourism and sustainable development. 
Additionally, the approach argues for the inclusion of all voices, particularly marginalised voices, and consistency among these voices at the outset of tourism planning and development. The third way approach, therefore, moves away from the two ends of the spectrum of neoliberalism and protectionism by proposing an alternative approach or arguing for a balance on the spectrum (Higgins-Desbiolles, 2006; Schilcher, 2007). Concomitantly, the approach proposes an alternative perspective regarding the two extreme dogmas of tourism being either a panacea for less-developed countries or the root of all their problems (Spenceley \& Meyer, 2012; Weaver, 2010). To this end, the third way approach is closely associated with a post-structural perspective (Scheyvens, 2007). Both these viewpoints seek an alternative approach to the other extreme, reductionist, conventional, polarised approaches. This alternative approach is developed based on the principles of participation, acknowledgement of multiple perspectives, and empowerment of marginalised voices.

The third space approach is widely employed in the realm of tourism interactions. According to Bhabha (1994, p.5), the third space is a space "between fixed identifications [that] opens up the possibility of a cultural hybridity that entertains difference without an assumed or imposed hierarchy". The approach allows tourism research to address the unbalanced power relations and different perspectives involved in tourism interactions (Leeming, 2016; Van der Duim, Peters, \& Wearing, 2005). Within the third space framework, tourism social actors are encouraged to move away from their pre-assumed, institutionalised, archaeological perspectives to acknowledge and appreciate the perspective of the Others (Hollinshead, 1998). Concomitantly, they detach themselves from pre-identified, fixed categories of identity to fully engage in a different culture. Additionally, the third space approach can facilitate a hybrid agora for cultural differentiation, eliminate inequitable power relationships and allow for change and the reconstruction of identity (Hunter, 2001; Wearing \& Wearing, 2006). Thus, this approach is argued to frame research on cultural practices in tourism, the representation of ethnicity in tourism interactions and the marketing of cultural attractions (Hollinshead, 1998). Indeed, many studies have affirmed the significance of the third space approach in addressing the polarities of authenticity versus inauthenticity and modern versus primitive in the commodification of CBT experiences (see Dolezal, 2011; Van der Duim et al., 2005). 
In this research, the third way approach and the third space approach are integrated to frame the proposal of a marketing strategy for the business sustainability of CBTEs in Vietnam. Based on the previously presented literature review, it is clear that within the domain of CBTE marketing, the aspects of stakeholder interventions, post-colonialism, and indigenous value marketisation and the dual objectives of CBTE sustainability are interrelated. These interrelated aspects regulate the entanglement of the domain of CBTE marketing in both CBT development and CBT marketing debates. Accordingly, the third way approach and the third space approach are integrated to promote the investigation of CBTE marketing for business sustainability. Due to its potential to reconcile the neoliberalism-protectionism antithesis, the third way approach is arguably a plausible way to frame the development of a marketing strategy for CBTE long-term success. In particular, the third way approach enables the reconciliation of polarised CBTE marketing strategies through its capacity to balance the dual objectives of CBTE sustainability in the proposed marketing strategy. Simultaneously, the third space approach can re-distribute power in tourism interactions and therefore is employed to guide the marketing relationships between local entrepreneurs and external intermediaries and reconcile the paradoxes in the marketisation of CBT products. Figure 1 summarises the theoretical framework of the study.

[Insert Figure 1 around here]

\section{Setting the scene: marketing practices for the business sustainability of CBTEs in Vietnam}

In Vietnam, the CBT concept was initiated in the early 2000s, in light of the political support of the central government and the financial assistance and advisory services of development agencies and NGOs. The potential of tourism for poverty alleviation was confirmed for the first time in the economic development strategy of 2001-2010 by the central authority, which consequently paved the way for the proliferation of CBT initiatives in the rural and mountainous regions of Vietnam (Truong, 2013). In their design, CBT initiatives in Vietnam have been oriented towards poverty alleviation purposes (Hummel, Gujadhur, \& Ritsma, 2013; Truong, Hall, \& Garry, 2014). Under the political support of the government, numerous international development agencies and NGOs facilitated donor-funded CBTEs for the propoor objectives. In addition to donor-aided CBTE projects, self-funded CBTEs or joint ventures 
with tour operators have flourished to meet the objective of increasing incomes among the community (Nguyen, 2016).

Compared with the remarkable growth of CBTEs in Vietnam, knowledge is limited about CBTE planning and development in Vietnam in general and CBTE marketing in particular. The available literature about this topic is mainly sourced from the handbooks and manuals published by CBT donors. These include the Toolkit on Poverty Alleviation through Tourism by the International Labour Organisation (ILO, 2012), the Guidance Manual for Developing Community-Based Tourism by the Asia Foundation (TAF, 2012), the Community-Based Tourism Development in Sapa, Vietnam reported by the Netherland Development Agency (SNV, 2003), and the Manual for Developing Rural Tourism in Vietnam by the Japanese International Cooperation Agency (JICA, 2013). These documents share an emphasis on marketing as an essential part of CBTE planning. However, none of these documents indicates an effort to elaborate on the components of a marketing strategy to guide CBTEs to achieve their long-term success. This lack of evidence-based guidance causes chaos and unsustainability in the marketing practices of CBTEs (Khoi, 2017; Nguyen, 2016).

With very little academic literature relating to the topic of CBT and marketing in the context of Vietnam, CBTEs have faced critical issues associated with their marketing efforts to connect their businesses with potential travellers. Local CBT entrepreneurs have an extreme inferior relationship with non-local tourism intermediaries in sales and marketing, resulting in tourism revenue leakage (Chau, 2014). Additionally, a contractual partnership with a sole tourism operator prevents a CBTE from appealing to other tourism intermediaries and increases the threat of supplier-distributor role exchange, as seen in the case of the Droong CBT village (Vietnam) (Ngo \& Doan, 2014). Through this case study, Ngo and Doan (2014) also found a failure in the communication tools of local entrepreneurs, a lack of quality in the CBTE's service offerings that prevents integration with mainstream tourism, and a lack of marketing strategies to attract the niche market of transformative tourism. Furthermore, the conventional perspective of seeing the "Other" as exotic prevails among CBTEs and Western visitors in their encounters in Vietnam (Stevens, 2010).

Thus, a marketing strategy framed by the principles of the dual objectives of CBTE sustainability, and that is capable of addressing the paradoxes in CBTE marketing is needed 
to guide the marketing practices of CBTEs in Vietnam. Such a mechanism is important for the long-term success of CBTEs in Vietnam and can contribute to the sustainability of tourism destinations at the grassroots level.

\section{Methodology}

\section{Methodological approach}

This study falls within the constructivist paradigm of qualitative research (Guba, 1990; Hollinshead, 2006) and utilised the knowledge co-production approach (Armitage et al., 2011; Jasanoff, 2004), which is characterised by a participatory methodology (Kindon, Pain, \& Kesby, 2007). According to Guba (1990), the constructivist approach admits that multiple realities that exist in the minds of the "insiders" and attempts to obtain one or a few constructions that are reconciled from different perspectives. Knowledge co-production refers to an interactive approach to knowledge generation in which researchers and research participants interact and influence each other to different degrees in generating knowledge, thus, the nature of the knowledge generated is considered to be socially constructed knowledge (Dale \& Armitage, 2011). Meanwhile, a participatory methodology refers to an inquiry-based approach in which relevant participants in a research project change and improve a problem by actively examining it together (Kindon et al., 2007).

This research paradigm has been widely advocated in tourism research involving multiple (and conflicting) perspectives. It helps to empower marginalised voices and practical wisdom in the research process, thereby enabling collaborative knowledge benefits, closing the research-practice gap and promoting the societal contributions of research (Carr et al., 2016; Espeso-Molinero et al., 2016; Nielsen \& Wilson, 2012).

The elaboration on marketing strategies for CBTE business sustainability in Vietnam is developed based on the principles of sustainable tourism marketing. Sustainable tourism marketing is "the application of marketing functions, processes and techniques to a destination, resource or offering, which serves the needs of the visitor and stakeholder community today and ensures the opportunities of future visitors and stakeholders to meet their needs in the future" (Font \& McCage, 2017, p.871). The principles of sustainable tourism 
marketing may be able to reconcile the dual objectives included in the paradoxical tourism problems of sustainable development, such as in national parks (Mitchell, Wooliscroft \& Higham, 2013; Wearing, Schweinsberg, \& Tower, 2016), heritage sites (Chhabra, 2009; Donohoe, 2012) and CBTEs (Ngo et al., 2018). Based on the concept of sustainable tourism marketing, different marketing strategy frameworks are developed, for instance, the 10Ps Marketing Mix of Pomering, Noble, \& Johnson (2011). The 10Ps Marketing Mix includes ten elements (i.e., product, price, place, promotion, participants, physical evidence, process, packaging, programming, and process) framed by a triple bottom line of sustainable tourism (i.e., sociocultural, environmental, and economic).

The marketing strategies of CBTEs are also driven by the nature of micro-sized enterprises (MsEs) in peripheral areas and community-based enterprises (CBEs), with which CBTEs are closely associated. CBEs are defined as an "entrepreneurial initiative that enhances the quality of life and economic development of a particular region" (Welsch \& Kuhns, 2002), p.3. Similarly, MsEs refer to those businesses of lesser than ten employees, and in the tourism context, most of the MsEs in rural settings are run by families (Banki \& Ismail, 2015; Chang, 2011; Hallenga-Brink \& Brezet, 2005; Jones \& Haven, 2005). In the tourism literature, three marketing strategies reiteratively highlighted in the discussions of MsEs and CBEs are customer segmentation, product design and product communication (see Chen, Lin, \& Kuo, 2013; Espeso-Molinero et al., 2016; Seixas \& Berkes, 2009; Williams \& Richter, 2002). Accordingly, in this paper, an analytical framework for CBTE marketing strategies in Vietnam is developed based on the abovementioned insights and is presented in Figure 2 .

[Insert Figure 2 around here]

\section{Data collection}

This study consisted of two stages, and the selection of research participants and the identification of research objectives in each stage are illustrated in the following subsections. Table 1 lists the research participants who participated in the interviews and workshop by stakeholder category.

[Insert Table 1 around here] 


\section{Stakeholder interviews}

In the first stage, CBTE stakeholders were interviewed to ascertain their perspectives about a proposed marketing strategy that promotes CBTE business sustainability. Interview participants were recruited using the purposive and snowball sampling methods. Purposive sampling functions to recruit relevant participants within a limited timeframe (Sekaran \& Bougie, 2016). In particular, this method was employed to identify the initial 21 participants for interviews. These participants were CBTE stakeholders directly involved in three CBTE projects, that is, Triem Tay Floating Restaurant, Thanh Toan Gardening and Cookery, and Minh Tho Homestay. The selection of three CBTEs for the investigation reflected a diversity of CBTE development and CBTE marketing approaches in Vietnam. In particular, Triem Tay Floating Restaurant, which was launched in June 2015, was self-evaluated as an infant enterprise. The business received marketing support from the Triem Tay CBTE co-operative and development agencies to appeal to tour operators and travellers. Thanh Toan Gardening and Cookery, which was established in 2012, achieved relatively substantial growth. The CBTE has gained regular flows of tourists and concurrent partnerships with several tour operators. Minh Tho Homestay was initiated in 2011 with the support of COHED, a Vietnam-based NGO. At the time of the investigation, Minh Tho Homestay had recovered its business with the sales and marketing assistance of CBT Travel, a travel agency specialised in CBT. The recovery was recorded after this business was confronted with difficulties in operations in a post-funding period. From the 21 original key participants, nine additional participants involved in CBT development in Vietnam were recruited via a snowball technique until the saturation of data was achieved. Altogether, thirty participants representing CBTE marketing stakeholders in Vietnam were interviewed (see Table 1). The interviews, which were in the form of face-toface and semi-structured conversations, occurred over four months, from November 2015 to February 2016.

The interviewees were asked their opinions on the marketing activities that CBTEs in Vietnam should undertake. The questions were centralised among the marketing of CBT experience, including the following: Who should be customers of CBTEs? What local entrepreneurs should "sell"? How should CBT products be designed? How could CBT products be promoted and communicated? The respondents were encouraged to justify their proposals by explaining 
how these marketing activities could be applicable to the context of Vietnam and could help CBTEs to achieve long-term success.

Workshop participants

Following the collaborative marketing aspects for CBTE business sustainability proposed through the interviews, an interactive workshop was conducted in Triem Tay Village (Quang Nam, Vietnam) on 17 March 2017. The workshop aimed to discuss the proposed marketing strategy's workability and to reach consensus on the alignment of the proposed strategies with CBTE long-term success. The thirty interview participants were invited to attend the workshop; only eight accepted the invitation. In light of the size of the group discussion and the representativeness of the stakeholder categories, three additional invitations were sent to other interested participants. Apart from the invitees, there were four unexpected participants who were CBTE stakeholders and wished to attend the workshop. Their requests were accepted, considering that the purpose of the workshop was knowledge interaction and sharing. Thus, a total of fifteen participants took part in the workshop (see the right column in Table 1). At the workshop, the proposed marketing strategies for the business sustainability of Vietnamese CBTEs, which were compiled from the Interview stage, were discussed and refined. The refinement was based on the compromise achieved by different stakeholder groups, the practicability in the context of Vietnam, the alignment with the principles of sustainable tourism marketing, and the possibility of balancing the dual objectives of CBTE business sustainability.

\section{Data analysis}

A content analysis was performed to identify, develop, and refine a marketing strategy for CBTE sustainability. In particular, the data collected from the interviews and workshop were transcribed verbatim and analysed to unravel the components of a marketing strategy for CBTE long-term success. The NVivo software package was used to facilitate the coding process. Indeed, the software functioned to group the respondent quotes into themes and to easily retrieve the data corresponding to a particular theme for analysis and evaluation. Specifically, three themes - market segmentation, product design and development and product communication and promotion - were identified through the data coding process. 


\section{Research findings: proposed marketing strategies for the business sustainability of CBTEs in Vietnam}

Through the data analysis, three marketing strategies for the business sustainability of CBTEs in Vietnam was proposed and are illustrated in the following subsections. These marketing strategies were identified based on the proposals raised through the stakeholder interviews and lately refined through the interactive workshop. As a result, three marketing aspects, i.e. market segmentation, product design and development and product promotion, were finalised. According to the research participants, these three marketing aspects represent crucial strategies to materialise a workable pathway for Vietnamese CBTEs to achieve longterm success.

Prioritising selective segmentation marketing techniques to appeal to appropriate travellers

In the realm of CBT development, the identification of potential appropriate travellers is essential because of the power of co-creation between CBTEs and travellers. Local entrepreneurs and CBT products and services are quite vulnerable to external interventions, of which travellers are an important source. Thus, the inclusion of appropriate travellers positively influences the long-term success of CBTEs.

In this respect, the adaptation of selective segmentation in marketing CBTEs is argued to facilitate business sustainability. The selective segmentation approach articulates the nature of CBT initiatives to the characteristics of travellers (Moscardo \& Murphy, 2016). The consistency between demand attributes and supply offerings can facilitate the business sustainability of CBTEs. Participant TO9 confirmed, "if we accept all travellers, CBT development will lead to a dead end".

Specifically, CBTE stakeholders suggested an appropriate segmentation for CBTEs in Vietnam consisting of well-educated, wealthy travellers who are interested in indigenous values and community benefits.

For the Vietnamese market, we should target medium- and high-income travellers [...]. They mostly live in developed countries [...], they are well-educated [...], they respect nature, and they would like to engage in conservations. (TO1) 
These responsible travellers could be accessed through international institutes on Fair Trade or development aids and responsible tour operators, as indicated by the respondent NGO7

We have successfully connected visitors sourced from Word Fair Trade Organisation and other NGOs to visit local handicraft businesses. [...] We have no worries about these visitors as they know how to behave well. With regards to other [international] visitors, we are selective through dealing with responsible tour operators only, for example, Buffalo [...].

In addition to international segments, local tourists were also a possible market for CBTEs to sustain their business. CBTEs have relatively more advantages in local markets than in international segments due to the similar context and culture (Zapata et al., 2011). Particularly, urban citizens and well-educated travellers should be targeted.

There are local markets for CBTEs in Vietnam. Those markets can be Vietnamese students studying overseas and well-educated urban travellers. These segments have good awareness about the principles of $C B T$, and their behaviour can be adjusted to harmonise with community values. (TO3)

Incorporating the dual objectives of sustainability in product design and development

According to the research participants, four components of product design and development were promoted: balancing indigenous values and market-driven components; setting service quality control as centralised; accounting for the included community fund; and aligning with the product frameworks established by CBTE networks.

In general, both indigenous values and market-driven components are essential for a CBT product (Espeso-Molinero et al., 2016). In particular, indigenous values are among the community assets that facilitate CBTE initiatives and the foundation of community identity, which is an ultimate goal guiding CBTE development models. Indigenous values including traditions, folklore, handicrafts, lifestyle and other natural-cultural-historical resources are types of social capital that encourage the participation of the community in tourism. Thus, indigenous values remain at the core of any marketing approach and regulate CBTE marketing strategies. 
We [the CBTE stakeholders] need to bear in mind that a key message in CBTE marketing campaigns is community values, which means indigenous culture, the lifestyle, and traditional crafts. (TS1)

Similarly, market-driven components foster the commercial attractiveness of CBTEs. As a tourism offering, CBT products cannot dismiss the imperativeness of customer-oriented marketing. Proper attention to market research can provide CBTEs with reliable insights to exploit indigenous values for tourism business. The importance of the tourism market orientation in CBT product development was acknowledged by the CBTE stakeholders, as demonstrated by an outstanding example of homestay accommodations. Homestay is a very popular tourism service offered by local entrepreneurs in less-developed countries. Facilitating homestay accommodation among CBTEs without carefully considering marketrelated issues is unlikely to lead to long-term success for CBTEs.

Those homestays that are conceptualised by putting together a room, an airconditioner, and a mattress are unlikely to attract tourists. (TO4)

We [the funding NGO supporting CBTEs in Nam Giang district, Vietnam] decided not to develop homestays in the village because our source of visitors is from Hoian [a touristic hub], which is just two-and-a-haft-hour travel from the community place. (NGO5)

It is necessary to clarify the level of integration of the two product component categories, i.e., indigenous components and market-driven attributes. While discussing this issue, there were three principles regulating CBT product design. First, satisfying the basic needs of travellers (i.e., safety, security and hygiene) was fundamental, framing the degree of integration of indigenous components and market-driven attributes in CBT product design.

Stilt houses [a popular kind of shelters for ethnic minorities in the mountainous regions of Vietnam] sharing the same dining and sleeping spaces cannot satisfy the issue of hygiene for visitors. (TO4) 
Second, a flexible combination of indigenous values and traveller demands was encouraged, in which the indigeneity in a CBT product and travellers' preferences were reconciled. The following example illustrated this point.

The Thai people (an ethnic minority group in Northern Vietnam) usually use "bong lau" [a local sedge] to make mattresses. This material might cause allergies to travellers and a mattress made of this material is very hard, which might displease travellers. (TO5)

Third, the position of indigenous values is at the core layer of product design whereas marketdriven components constitute augmented layers. The central position of indigenous values in CBT product design reflects community resilience in tourism engagement and represents an orientation towards the preservation of indigenous values and the representation of community identity in CBT initiatives. Similarly, the market orientation in augmented layers should be designed flexibly to adjust to different market segments. The flexibility of augmented layers is a marketing technique for maximising the trading volume without altering the principles of $\mathrm{CBT}$.

He [CBT Travel's founder who sponsors marketing for Minh Tho homestay] provides us [tour operators] with information about the different services offered by the homestay rather than pre-designed itineraries. The flexibility in service offerings helps us select suitable services for our target customers. (TO3)

Service quality management is positioned at the centre of product design and development to tackle the paradoxical linkage between local entrepreneurs and economic incentives. This paradox is exemplified in this research through the relations between local CBT entrepreneurs and product pricing. As perceived by the participants of this study, there are issues of price wars among homestays, pricing exploitation by predatory tour operators, and inconsistencies among local entrepreneurs regarding the price of products.

In Lac village [a mountainous village in Vietnam], there are numerous homestays, and homestay owners can easily drop the accommodation fare down to VND 
$20,000^{+}$, VND 10,000, or even VND 5,000. Accordingly, the service quality decreases, too. Also, the villagers [who are Thai people] sell Chinese souvenirs or those products of unknown origins [that result in an erosion of Thai culture]. (DA1)

When I started the business, I had no idea how much it [gardening service] should be priced. Instead, tour operators gave an offer, and I just accepted it. However, later on, I found that with that price, I worked without profits. (LE2)

We made a five-year agreement with the village [Bohoong] about service prices, with periodic reviews. However, the villagers kept requiring extra money for service offerings constantly. (TO10)

Thus, a pricing strategy should be included in a CBTE's product design and development to satisfy the economic motivations of local communities engaging in the tourism business and to minimize tourism economic misconduct that negatively impacts the sustainable development of local livelihoods. In particular, a relatively high price of CBT products compared to the market price can reduce the commercial appeal of CBTEs, thereby threatening their business' self-financing. Participant TO7 stated,

Local entrepreneurs usually adopt an indigenous viewpoint in pricing. They value a hand-weaving tapestry based on their working hours on it and its significance in their culture. That viewpoint sometimes generates a relatively higher price for the tapestry than the price range designated by travellers for a souvenir.

Simultaneously, a relatively low price of CBT products compared to the market price can decrease the economic potential that tourism can offer to local communities. A tourist supplier gave an example.

I asked a coffee shop owner in the village [Boohong, Dong Giang, Vietnam] how much he is selling a bottle of beer for and the answer was VND 10,000. In Vietnam, every tourist expects to pay VND 20,000 for a beer [...], so, I advised him that he should charge up to that price, too. (TS2)

\footnotetext{
+ US\$ 1 is equal to approximately VND 22,000
} 
Accordingly, service quality control should be at the centre of product design and development. Service quality control makes the abovementioned balanced pricing strategy feasible. Thus, CBTEs should embed in their pricing strategies a commitment to service quality management. Provided that the CBT products of a CBTE are of the appropriate quality, the proposed price of its products and services will be reasonable. The study participants illustrated this point as follows:

CBTEs need to convince tour operators that their proposed price is aligned with their guaranteed service quality control. (DA1)

We [tour operators] will accept offers from CBTEs if they can clarify what comes up to that price. (TO6)

CBT product design and development should also include a contribution to the community fund. In this study, the participants argued for the necessity of a community fund to maintain the nature of CBTEs, reduce resentment among community members and reflect the business ethics of local entrepreneurs. Additionally, the fund should be approved by the local entrepreneurs, be acknowledged by the local government, and be explained to tour operators and travellers.

We train the locals to mark up $7 \%$ of the final price of a handicraft product for the community fund for sustainable development. (NGO7)

Because I [the business entrepreneur] am a part of the community [Thanh Toan village], I think I should give back to the community [through a contribution to the community fund]. (LE2)

The community fund can be used for the community's functional activities (e.g., family visits) and for children's activities. (TO3)

CBT product design and development should also be aligned with the product frameworks established by CBTE networks in consultation with external stakeholders (e.g., tour operators and the government). The participants in this study particularly noted the role of networks in 
CBTE marketing strategies through the suggestion of having a shared pricing framework for homestays and other CBT product lines within a destination at national or regional levels.

The framework will act as a reference for CBTEs to convey a clear message to tour operators about CBT prices and simultaneously diminish the predatory behaviours of tour operators. (DA1)

A pricing framework helps to avoid price-cutting behaviour of local entrepreneurs. (TO3)

\section{Building a sustainable promotion strategy for CBTEs}

With regard to the promotion strategy for CBTEs, two factors were discussed. They included empowering young community members in promoting CBTEs via social media and building a grid of marketing intermediaries.

Social media plays a crucial role in promoting CBTEs (Mkono, 2016). That perception was well confirmed in the present study. In particular, the research participants highlighted the role of online marketing, specifically social media, and they commented that a static website, regardless of its suitability to the limited computer literacy of local communities, was not effective for promoting CBTEs. Instead, updated websites and Facebook were preferable. Participant TO6 stated, "Regarding websites and Facebook, it is important that these media be maintained and updated. There needs to be personnel to respond [to visitors' requests] and to update information." Accordingly, the involvement of young people in a community to address the challenge was suggested. Their commitment to managing these social media could facilitate the connections among different generations in CBT development, which is crucial for the long-term success of CBTEs. A participant (DA2) said,

The limited communication capacity of CBTEs regarding social media can be addressed owing to some active members in the community who are young, educated and experienced with these tools. To this end, the gap between CBTEs and the market can be shortened. 
Additionally, regardless of the predominance of information exchanges via online social media platforms, the participants in this research still affirmed the significance of marketing intermediaries for CBTE sustainability. In particular, a grid of marketing intermediaries (instead of binary, dyadic, monopolised linkages) was suggested in order to provide alternative conduits that connect CBTEs and potential travellers, booster the relationships between CBTEs and tour operators, and assist in particularising selective segmentation marketing techniques.

We [the funding NGO supporting CBTEs in Nam Giang] target group inclusive tours via tour operators because tour operators will help to filter appropriate guests for CBTEs, thereby minimising damaging impacts on the community. (NGO5)

Craftlink works as the intermediary of CBT activities, linking local artisans to travellers sourced from WFTO [World Fair Trade Organisation where Craftlink is membered] and NGOs. We have facilitated the relationships between artisan groups and responsible tour operators. We are planning to work with tour operators to attract Vietnamese travellers experiencing handicraft values under responsible tourism initiatives. (NGO7)

The voices of UNESCO and ILO [two international organisations providing assistance on CBT development in Vietnam] are powerful. Thus, they can invite influential tour operators to come to the table together with local entrepreneurs. (TO1)

\section{Discussion}

The principles of the third way approach and the third space approach embedded in the proposed marketing strategies are examined in this study. Simultaneously, the applicability of the proposed marketing strategies in addressing the objectives of CBTE business sustainability are argued.

With regard to the third way approach, this study argues for the approach's attributes of contextualisation, participation, empowerment and reconciliation in the context of CBT development. The proposed marketing strategies reflect the contextualisation of CBT development, in which economic and socio-cultural backgrounds and local entrepreneurs' 
characteristics are accounted for. The CBT literature indicated that a one-size-fits-all strategy that could successfully fit all CBT initiatives is not available (Davidson - Hunt, Turner, Berkes, \& Turner, 2012; Fletcher, Pforr, \& Brueckner, 2016). Accordingly, in the proposed marketing strategies, a grid of marketing intermediaries remains relevant for Vietnamese CBTEs because of the intermediaries' marketing know-how, which can make-up for the marketing shortage among local entrepreneurs and bridge the language barriers between local entrepreneurs and potential travellers (Truong et al., 2014). The inclusion of a community fund in product pricing and using an established CBT pricing framework for products arguably respond to the economic vulnerabilities of local entrepreneurs in Vietnam (Truong et al., 2014), thereby balancing idealism and pragmatism in proposing CBTE marketing initiatives. In addition, the participatory and empowerment attribute of the third way approach is exemplified through the proposal of empowering young community members to market CBTEs, which can enhance CBTEs' business capacity and bolster their long-term success. To this end, the current study concurs with previous studies that have advocated an indigenised strategy in CBT development in which local people are involved in tourism entrepreneurships more actively through indigenous-based approaches (Holmes, Grimwood, King, \& Nation, 2016; EspesoMolinero et al., 2016). Similarly, compromises between appropriate customers and segment sizes through selective segmentation marketing and validation of service quality control at the core of product design can indicate the capability of the approach to balance dichotomous CBTE marketing strategies. With regards to paradoxical domains, such as CBT development, reconciliation with and attentions to concurrent objectives are necessary to address the domains successfully (Chhabra, 2009; Mitchell, Wooliscroft, \& Higham, 2013).

The third space is activated in the proposed marketing strategies through deconstructing, to a certain degree, archaeological representations that occur in the context of CBTE marketing. First, we argue that, in the proposed marketing strategies, the host-guest relationships are better balanced. This balance is achieved by targeting travellers who have a sense of care for the communities they visit and focusing on indigenous values at the core of product development. Recent studies have demonstrated that indigenous value sharing could empower local entrepreneurs in relations with tourists and influence on transformative changes in tourists (Walker \& Moscardo, 2016; Wright, Suchet-Pearson, Lloyd, Burarrwanga, \& Burarrwanga, 2009). Second, the marketing relationships between local entrepreneurs and 
external stakeholders are re-directed in the proposed marketing strategies. The grid of distribution channels included in the strategies may break down the dominant-submissive dichotomy that prevails in CBTE-tourism operator linkages and eliminate the neo-colonial approach in CBT development (Tolkach \& King, 2015).

By identifying marketing strategies for the business sustainability of CBTEs in Vietnam, this study argues for the importance of acknowledging and integrating ideological and developmental alternatives to CBTEs in less-developed countries. The abovementioned discussions indicated that the market failure of CBTEs could be better addressed through adequate attentions to the dilemmatic nature of $\mathrm{CBT}$ development and the paradox of ideological aspects. Thus, this study, together with recent endeavours (Espeso-Molinero et al., 2016; Ngo et al., 2018; Ngo et al., 2019; Sakata \& Prideaux, 2013), support the significance of ideological changes and development alternatives and their connections to CBT.

Practical contributions are addressed in the study. Indeed, the marketing strategies proposed in this paper are regarded as among the initial attempts to redress the unsustainability of CBTEs in less-developed countries through the lens of sustainable tourism marketing. To this end, this study responds to the need for practical models that are capable to transform the philosophies of sustainable tourism marketing into corporate marketing plans (Donohoe, 2012). Within the context of Vietnam, the findings from this study provide a socially robust, evidence-based reference for NGOs and development agencies attempting to use marketbased tools to realise social missions. The proposed marketing strategies may also assist selffunded CBTEs in their marketing decisions to secure their position in the marketplace over the long-term.

\section{Conclusions}

This paper aims to investigate a marketing strategy oriented towards the business sustainability of CBTEs in Vietnam. Accordingly, three tailor-made strategies for marketing CBTEs intended to yield long-term success are identified. First, selective segmentation marketing techniques are preferred to appeal to the appropriate travellers. Second, CBT product design and development should embrace indigenous values at the core layers and market-driven attributes at the augmented layers, establish a centralised mechanism for 
service quality control in the product design, account for the inclusion of a community fund, and align with a pricing framework established by CBTE networks. Third, among the communication and promotion strategies of CBTEs, young community members can promote CBTEs through social media and a grid of marketing intermediaries should be encouraged. These proposed CBTE marketing initiatives are regarded as among the initial attempts to redress the unsustainability of CBTEs in Vietnam. Because CBT research has predominantly focused on critical evaluations without including solutions, the findings of this research are timely and significant with regard to practice.

Through the proposed marketing strategy, the significance of integrating the third way approach and third space approach to better address the wicked-natured domains in CBT development is exemplified. In particular, the proposed marketing strategies provide the capacity to fulfil the dual objectives of CBTE sustainability, encourage collaborative advantages, consider contextual situations and balances the power relations between local CBT entrepreneurs and marketing intermediaries and between host and tourists.

This study also has some limitations, and therefore, avenues for future research can be suggested. The current study elaborated the most crucial marketing aspects of CBTEs in Vietnam and other similar contexts. Future research can further investigate these marketing topics to deliver CBTEs with action plans. For instance, studies on value-based marketing strategies that are designed based on host-guest encounters for their mutual benefits and learning would be valuable.

\section{References}

Afenyo, E. A., \& Amuquandoh, F. E. (2014). Who Benefits from Community-based Ecotourism Development? Insights from Tafi Atome, Ghana. Tourism Planning \& Development, 11(2), 179-190.

Armitage, D., Berkes, F., Dale, A., Kocho-Schellenberg, E., \& Patton, E. (2011). Comanagement and the co-production of knowledge: Learning to adapt in Canada's Arctic. Global Environmental Change, 21(3), 995-1004. 
Banki, M. B., \& Ismail, H. N. (2015). Understanding the characteristics of family owned tourism micro businesses in mountain destinations in developing countries: evidence from Nigeria. Tourism Management Perspectives, 13, 18-32.

Berkes, F. (2009). Indigenous ways of knowing and the study of environmental change. Journal of the Royal Society of New Zealand, 39(4), 151-156

Bhabha, H. K. (1994). The location of culture. London: Routledge.

Burns, P. M. (2004). Tourism planning: A third way? Annals of Tourism Research, 31(1), 24-43.

Carr, A., Ruhanen, L., \& Whitford, M. (2016). Indigenous peoples and tourism: the challenges and opportunities for sustainable tourism. Journal of Sustainable Tourism, 24(8-9), 10671079.

Chang, J. (2011). Introduction: Entrepreneurship in tourism and hospitality: The role of SMEs. Asia Pacific Journal of Tourism Research, 16(5), 467-469.

Chau, H. N. M. (2014). Stakeholder networks supplying rural tourism in Vietnam: with reference to a Japanese case (Doctoral Dissertation). Okayama University, Japan. Retrieved from

http://ousar.lib.okayamau.ac.jp/files/public/5/52622/201605281143252645/K0004988 fulltext.pdf.

Chen, L.-C., Lin, S.-P., \& Kuo, C.-M. (2013). Rural tourism: Marketing strategies for the bed and breakfast industry in Taiwan. International Journal of Hospitality Management, 32, 278-286.

Chhabra, D. (2009). Proposing a sustainable marketing framework for heritage tourism. Journal of Sustainable Tourism, 17(3), 303-320.

Dale, A., \& Armitage, D. (2011). Marine mammal co-management in Canada's Arctic: knowledge co-production for learning and adaptive capacity. Marine Policy, 35(4), 440-449.

Davidson-Hunt, I. J., Turner, K. L., Berkes, F., \& Turner, N. J. (2012). Indigenous perspectives on ecotourism development: a British Columbia case study. Journal of Enterprising Communities: People and Places in the Global Economy. 
Dixey, L. M. (2008). The unsustainability of community tourism donored projects: Lessons from Zambia. In A. Spenceley (Ed.), Responsible tourism: Critical issues for conservation and development. London: Earthscan.

Dodds, R., Ali, A., \& Galaski, K. (2016). Mobilizing knowledge: Determining key elements for success and pitfalls in developing community-based tourism. Current Issues in Tourism, 1-22.

Dolezal, C. (2011). Community-based tourism in Thailand:(Dis-)illusions of authenticity and the necessity for dynamic concepts of culture and power. Austrian Journal of South-East Asian Studies, 4(1), 129-138.

Donohoe, H. M. (2012). Sustainable heritage tourism marketing and Canada's Rideau Canal world heritage site. Journal of Sustainable Tourism, 20(1), 121-142.

Dredge, D., Hales, R., \& Jamal, T. (2013). Community case study research: Researcher operacy, embeddedness, and making research matter. Tourism Analysis, 18(1), 29-43.

Espeso-Molinero, P., Carlisle, S., \& Pastor-Alfonso, M. J. (2016). Knowledge dialogue through Indigenous tourism product design: a collaborative research process with the Lacandon of Chiapas, Mexico. Journal of Sustainable Tourism, 24(8-9), 1331-1349.

Evans, G., \& Cleverdon, R. (2000). Fair trade in tourism-community development or marketing tool. In G. Richards \& D. Hall (Eds.), Tourism and sustainable community development (pp. 137-153). UK: Routledge.

Fletcher, C., Pforr, C., \& Brueckner, M. (2016). Factors influencing Indigenous engagement in tourism development: an international perspective. Journal of Sustainable Tourism, 1-21.

Giddens, A. (1998). The third way: The renewal of social democracy. Cambridge: Polity Press. Guba, E. G. (1990). The paradigm dialog. Newbury Park, CA: Sage Publications.

Hall, M. C., \& Tucker, H. (2004). Tourism and postcolonialism: Contested discourses, identities and representations. London: Routledge. 
Hallenga-Brink, S., \& Brezet, J. (2005). The sustainable innovation design diamond for microsized enterprises in tourism. Journal of Cleaner Production, 13(2), 141-149.

Häusler, N. (2008). Community-based Tourism (CBT)-What works and what does not work? Drawing on experiences in South America and Asia. Paper presented the Presentation at the 2nd International Conference on Responsible Tourism in Destinations.

Higgins-Desbiolles, F. (2006). More than an "industry": The forgotten power of tourism as a social force. Tourism Management, 27(6), 1192-1208.

Hollinshead, K. (1998). Tourism, hybridity, and ambiguity: The relevance of Bhabha's 'third space'cultures. Journal of Leisure Research, 30(1), 121-156.

Hollinshead, K. (2006). The shift to constructivism in social inquiry: Some pointers for tourism studies. Tourism Recreation Research, 31(2), 43-58.

Holmes, A. P., Grimwood, B. S., King, L. J., \& Nation, L. K. e. D. F. (2016). Creating an Indigenized visitor code of conduct: The development of Denesoline self-determination for sustainable tourism. Journal of Sustainable Tourism, 24(8-9), 1177-1193.

Hummel, J., Gujadhur, T., \& Ritsma, N. (2013). Evolution of Tourism Approaches for Poverty Reduction Impact in SNV Asia: Cases from Lao PDR, Bhutan and Vietnam. Asia Pacific Journal of Tourism Research, 18(4), 369-384.

Hunter, W. C. (2001). Trust between culture: The tourist. Current Issues in Tourism, 4(1), 4267.

ILO. (2012). Bộ công cụ hướng dẫn giảm nghèo thông qua du lịch [Toolkit on poverty alleviation through tourism]. Hanoi: International Labour Organisation Vietnam.

IMF (2015, April). World Economic Outlook: Database-WEO Groups and Aggregates Information. Retrieved from https://www.imf.org/external/pubs/ft/weo/2015/01/weodata/index.aspx. 
Jasanoff, S. (2004). States of knowledge: the co-production of science and the social order. London: Routledge.

JICA. (2013). Cẩm nang thực tiễn phát triển du lịch nông thôn Việt Nam [Manual for developing rural tourism in Vietnam]. Hanoi: Japanese International Cooperation Agency.

Jones, E., \& Haven, C. (2005). Tourism SMEs, Servive quality and Destination competitiveness. In E. Jones \& C. Haven (Eds.), Tourism SMEs, service quality, and destination competitiveness. Wallingford: $C A B I$.

Khoi. (2017). Cần Thơ: Khai thác du lịch cộng đồng đang "rối như canh hẹ" [Can Tho: Chaos in CBT management]. Entrepreneurship Forum. Retrieved from http://enternews.vn/can-thokhai-thac-du-lich-cong-dong-dang-roi-nhu-canh-he-115150.html.

Kindon, S., Pain, R., \& Kesby, M. (2007). Participatory action research approaches and methods: Connecting people, participation and place. New York: Routledge.

Kontogeorgopoulos, N., Churyen, A., \& Duangsaeng, V. (2013). Homestay tourism and the commercialization of the rural home in Thailand. Asia Pacific Journal of Tourism Research, 20(1), 29-50.

Koot, S. P. (2016). Contradictions of capitalism in the South African Kalahari: Indigenous Bushmen, their brand and baasskap in tourism. Journal of Sustainable Tourism, 24(8-9), 12111226.

Leeming, J. (2016). Addressing cultural vulnerabilities in arctic tourism: kindness as' third space'. Master's thesis, University of Waterloo, Ontario, Canada.

Malatji, M. I., \& Mtapuri, O. (2012). Can Community-Based tourism enterprises alleviate poverty? toward a new organization. Tourism Review International, 16(1), 1-14.

Manyara, G., \& Jones, E. (2005). Policy options for the development of an indigenous tourism SME sector in Kenya. In E. Jones \& C. Haven (Eds.), Tourism SMEs, service quality, and destination competitiveness (pp. 59-72). London: CABI. 
Manyara, G., \& Jones, E. (2007). Community-based Tourism Enterprises Development in Kenya: An Exploration of Their Potential as Avenues of Poverty Reduction. Journal of Sustainable Tourism, 15(6), 628-644.

Mielke, E. J. C. (2012). Community based tourism: Sustainability as a matter of result management. In G. Lohmann \& D. Dredge (Eds.), Tourism in Brazil (p.3-43). London: Taylor \& Francis.

Mitchell, J., \& Muckosy, P. (2008). A misguided quest: Community-based tourism in Latin America. London: Overseas Development Institute.

Mitchell, R., Wooliscroft, B., \& Higham, J. E. (2013). Applying sustainability in national park management: Balancing public and private interests using a sustainable market orientation model. Journal of Sustainable Tourism, 21(5), 695-715.

Mkono, M. (2016). Sustainability and Indigenous tourism insights from social media: worldview differences, cultural friction and negotiation. Journal of Sustainable Tourism, 24(89), 1315-1330.

Ngo, T., \& Doan, T. (2014). Market access and the sustainability of community based tourism enterprises: Case study in Droong village, Dong Giang district, Quang Nam province, Vietnam. Paper presented at the International conference on sustainable development and ethnic minority poverty reduction in mountainous regions of Vietnam, Thai Nguyen, Vietnam.

Ngo, T., Hales, R., \& Lohmann, G. (2019). Collaborative marketing for the sustainable development of community-based tourism enterprises: Reconciliation of diverse perspectives. Current Issues in Tourism, 22(18), 2266-2283.

Ngo, T., Lohmann, G., \& Hales, R. (2018). Collaborative marketing for the sustainable development of community-based tourism enterprises: voices from the field. Journal of Sustainable Tourism, 26(8), 1325-1343.

Nguyen. (2016). Nghiên cứu kinh nghiệm phát triển du lịch cộng đồng ở một số địa phương tại Việt Nam [CBT development in different parts of Vietnam: An experiential study]. Institute for Tourism Development Research. Retrieved from http://www.itdr.org.vn/vi/kinh-nghiem- 
ptdl/kinh-nghiem-trong-nuoc/1216-xay-dung-mo-hinh-du-lich-cong-dong-trong-phat-triencua-dia-phuong-va-kinh-nghiem-phat-trien-du-lich-cong-dong-o-mot-so-dia-phuong.html.

Nielsen, N., \& Wilson, E. (2012). From invisible to indigenous-driven: A critical typology of research in indigenous tourism. Journal of Hospitality and Tourism Management, 19(1), 6775.

Notzke, C. (2004). Indigenous tourism development in southern Alberta, Canada: tentative engagement. Journal of Sustainable Tourism, 12(1), 29-54.

Okazaki, E. (2008). A community-based tourism model: its conception and use. Journal of Sustainable Tourism, 16(5), 511-529.

Öniş, Z., \& Şenses, F. (2005). Rethinking the emerging post-Washington consensus. Development and change, 36(2), 263-290.

Phommavong, S., \& Sörensson, E. (2012). Ethnic tourism in Lao PDR: gendered divisions of labour in community-based tourism for poverty reduction. Current Issues in Tourism, 17(4), 350-362.

Pomering, A., Noble, G., \& Johnson, L. W. (2011). Conceptualising a contemporary marketing mix for sustainable tourism. Journal of Sustainable Tourism, 19(8), 953-969.

Reggers, A., Grabowski, S., Wearing, S. L., Chatterton, P., \& Schweinsberg, S. (2016). Exploring outcomes of community-based tourism on the Kokoda Track, Papua New Guinea: a longitudinal study of Participatory Rural Appraisal techniques. Journal of Sustainable Tourism, 24(8-9), 1139-1155.

Sakata, H., \& Prideaux, B. (2013). An alternative approach to community-based ecotourism: a bottom-up locally initiated non-monetised project in Papua New Guinea. Journal of Sustainable Tourism, 21(6), 880-899.

Schéou, B., \& Southon, A. (2013). Ambiguities and difficulties in partnership relations: the case of 'fair tourism' in Western Africa. Current Issues in Tourism, 16(7-8), 753-772. 
Scheyvens, R. (2007). Exploring the tourism-poverty nexus. Current Issues in Tourism, 10(2), 231-254.

Schilcher, D. (2007). Growth versus equity: The continuum of pro-poor tourism and neoliberal governance. Current Issues in Tourism, 10(2-3), 166-193.

Seixas, C. S., \& Berkes, F. (2009). Community-based enterprises: The significance of partnerships and institutional linkages. International Journal of the Commons, 4(1), 183-212.

Sekaran, U., \& Bougie, R. (2016). Research methods for business: A skill building approach. West Succex, UK: John Wiley \& Sons.

SNV (2003). Community-based tourism development in Sapa, Vietnam. Hanoi: SNV Netherlands Development Organisation.

Snyman, S. (2014). Partnership between a private sector ecotourism operator and a local community in the Okavango Delta, Botswana: the case of the Okavango Community Trust and Wilderness Safaris. Journal of Ecotourism, 13(2-3), 110-127.

Spenceley, A., \& Meyer, D. (2012). Tourism and poverty reduction: Theory and practice in less economically developed countries. Journal of Sustainable Tourism, 20(3), 297-317.

Stevens, M. (2010). Power disparities and community-based tourism in Vietnam. In S. Gmelch (Ed.), Tourists and Tourism: A Reader. 2nd edition. Long Grove: Waveland Press.

TAF (2012). Tài liệu hướng dẫn phát triển du lịch cộng đồng [Guidance manual for developing community-based tourism]. Hanoi: The Asia Foundation.

Tasci, A., Croes, R., \& Bartels Villanueva, J. (2014). Rise and fall of community-based tourism - facilitators, inhibitors and outcomes. Worldwide Hospitality and Tourism Themes, 6(3), 261276.

Taylor, S. R. (2014). Maya cosmopolitans: engaging tactics and strategies in the performance of tourism. Identities: Global Studies in Culture and Power, 21(2), 219-232. 
Tolkach, D., \& King, B. (2015). Strengthening Community-Based Tourism in a new resourcebased island nation: Why and how? Tourism Management, 48, 386-398.

Torres, R. M., Skillicorn, P., \& Nelson, V. (2011). Community Corporate Joint Ventures: An Alternative Model for Pro-Poor Tourism Development. Tourism Planning \& Development, 8(3), 297-316.

Truong, V. D. (2013). Tourism policy development in Vietnam: a pro-poor perspective. Journal of Policy Research in Tourism, Leisure and Events, 5(1), 28-45.

Truong, V. D., Hall, C. M., \& Garry, T. (2014). Tourism and poverty alleviation: perceptions and experiences of poor people in Sapa, Vietnam. Journal of Sustainable Tourism, 22(7), 10711089.

Van der Duim, R., Peters, K., \& Wearing, S. (2005). Planning host and guest interactions: Moving beyond the empty meeting ground in African encounters. Current Issues in Tourism, 8(4), 286-305.

Van Der Duim, V. R., \& Caalders, J. (2008). Tourism chains and pro-poor tourism development: an actor-network analysis of a pilot project in Costa Rica. Current Issues in Tourism, 11(2), 109-125.

Walker, K., \& Moscardo, G. (2016). Moving beyond sense of place to care of place: the role of Indigenous values and interpretation in promoting transformative change in tourists' place images and personal values. Journal of Sustainable Tourism, 24(8-9), 1243-1261.

Wearing, S. L., Schweinsberg, S., \& Tower, J. (2016). Marketing national parks for sustainable tourism. Bristol, UK: Channel View Publications.

Wearing, S., \& Wearing, M. (2006). "Rereading the subjugating tourist" in neoliberalism: postcolonial otherness and the tourist experience. Tourism Analysis, 11(2), 145-162.

Weaver, D. (2010). Community-based tourism as strategic dead-end. Tourism Recreation Research, 35(2), 206-208. 
Welsch, H. P., \& Kuhns, B. A. (2002). Community-based enterprises: propositions and cases. Paper presented at the conference USASBE 2002 : an entrepreneurial bonanza. Reno, Nevada: USA.

Williams, P. W., \& Richter, C. (2002). Developing and Supporting European Tour Operator Distribution Channels for Canadian Aboriginal Tourism Development.pdf. Journal of Travel Research, 40, 404-415.

Wright, S., Suchet-Pearson, S., Lloyd, K., Burarrwanga, L. L., \& Burarrwanga, D. (2009). 'That means the fish are fat': Sharing experiences of animals through Indigenous-owned tourism. Current Issues in Tourism, 12(5-6), 505-527.

Zapata, M. J., Hall, C. M., Lindo, P., \& Vanderschaeghe, M. (2011). Can community-based tourism contribute to development and poverty alleviation? Lessons from Nicaragua. Current Issues in Tourism, 14(8), 725-749. 